\title{
LA NEGOCIACIÓN EN LOS CONFLICTOS AMBIENTALES Y SU IMPLICANCIA EN EL DESARROLLO LOCAL: CASO DE LA COMUNIDAD AYMARA DE CANCOSA
}

\author{
NEGOTIATION IN ENVIRONMENTAL CONFLICTS AND THEIR IMPLICATIONS \\ FOR LOCAL DEVELOPMENT: CASE OF THE AYMARA COMMUNITY \\ OF CANCOSA
}

\author{
Daniela Escalona Thomas*
}

\begin{abstract}
A pesar de que en Chile no existen mecanismos institucionalizados de mediación de conflictos ambientales, la Resolución Negociada de Conflictos Ambientales (RNCA) opera de manera informal. Este artículo analiza las diversas posturas frente a los mecanismos de RNCA, para posteriormente a través del estudio de la negociación de la comunidad aymara de Cancosa frente a la minera BHP-Billiton, establecer que esta estrategia de gestión de conflictos no tiene los resultados esperados en relación con la participación y el reconocimiento de las comunidades locales como tránsito hacia su desarrollo. Por el contrario, las consecuencias de la negociación constituyen rupturas en el devenir comunitario, especialmente cuando se trata de comunidades indígenas.

Palabras claves: Conflicto ambiental, judicialización y negociación, Resolución Negociada de Conflictos AmbientalesRNCA, comunidades indígenas.
\end{abstract}

Despite the fact that in Chile there are no institutionalized mechanisms for mediating environmental conflicts, the Environmental Dispute Resolution (EDR) operates informally. This article analyzes different positions regarding the mechanisms of EDR. By studying the case of the negotiation of the Aymara Community in Cancosa with the mining company BHP-Billiton reveals that this strategy of conflict management does not have the expected outcomes in terms of participation and recognition of local communities as a way to their development. On the contrary, the consequences of the negotiation constitute ruptures in the community development, especially when dealing with indigenous communities.

Key words: Environmental conflict, judicialization and negotiation, Environmental Dispute Resolution-EDR, compensation, indigenous communities.

La expansión del extractivismo en América Latina a partir de la década de los noventa, responde a un proceso que ocurre en países subdesarrollados con propósitos de incrementar el crecimiento económico como elemento fundamental para alcanzar el desarrollo. Forma parte de la visión contemporánea del desarrollismo latinoamericano, puesto que se conserva el mito del progreso y desarrollo bajo una nueva hibridación cultural y política (Gudynas, 2009 y 2010; Acosta 2012). Este proceso se caracteriza por (i) la explotación intensiva y a gran escala de recursos naturales renovables y no renovables, (ii) la escasa diversificación económica de los territorios donde se instala produciendo una lógica de ocupación de los territorios destructiva, (iii) un grado de procesamiento nulo o mínimo y finalmente, (iv) los bienes que se extraen se destinan fundamentalmente hacia la exportación (Gudynas, 2009;
Acosta, 2012; Svampa, 2013). Su implementación se origina en ciertas medidas que adoptan los países, entre las que cuentan: disminución de la carga impositiva como un estímulo a la inversión, otorgamiento de facilidades para la repatriación de utilidades, así como la reducción de exigencias ambientales y laborales (Gudynas, 2010; Acosta, 2010).

Aquella transformación ha ocurrido en un escenario donde las externalidades negativas de la actividad extractiva se distribuyen de manera desigual. De este modo, comunidades tradicionales especialmente indígenas, han tenido que asumir los efectos negativos producidos por el sector: migración, abandono de territorios comunitarios y desaparición de actividades económicas y culturales tradicionales. Así, han debido movilizarse y enfrentar a autoridades y empresas, produciéndose con ello una oleada de conflictos ambientales.

\footnotetext{
* Pontificia Universidad Católica de Chile, Centro de Estudios Interculturales e Indígenas. Santiago, Chile. Correo electrónico: daniela.escalonathomas@gmail.com
} 
Esta situación de conflictividad territorial se ha profundizado por la poca incidencia política de estos grupos frente a las empresas transnacionales, así como debido al precario apoyo institucional del Estado.

En este contexto, el conflicto de la comunidad aymara de Cancosa, está relacionado con el desecamiento de los bofedales situados en la Pampa Lagunillas ubicadas dentro del fundo Huantija (DL N ${ }^{\circ} 67,2001$ ) parte de los territorios comunitarios, emplazado a $4.200 \mathrm{msnm}$ y distante unos 50 kilómetros del yacimiento minero (Larraín y Poo, 2010). Estas lagunas altiplánicas desde 1991 abastecen de agua a las actividades del proyecto Cerro Colorado, una mina de cobre a rajo abierto actualmente propiedad de la transnacional BHP-Billiton, momento en el cual la comunidad arrienda a la Compañía Minera Cerro Colorado (CMCC) parte de las tierras indígenas para la explotación de recursos hídricos por 30 años (Mamani, 2008).

En 2002, los comuneros se dan cuenta de que Lagunillas, mostraba graves signos de desecación, "nos dimos cuenta que el bofedal de Lagunillas se nos secó, las vertientes, los hitos de agua se secó, ahí recién tuvimos problemas con la compañía" (dirigente, hombre tercera edad, julio del 2015). Frente a lo cual inician una serie de acciones: denuncias públicas, denuncias a las autoridades competentes para finalmente dar inicio a un proceso judicial, que se cierra debido a una negociación privada que sostienen con la empresa. Adicionalmente y motivado tanto por la fiscalización ambiental como por el acuerdo con la comunidad, la empresa se compromete a reparar el daño ambiental, lo que hasta hoy no se ha cumplido satisfactoriamente.

Este hecho, marca un precedente en cuanto a las negociaciones de conflictos ambientales en el país (Romero-Toledo et al., 2017), puesto que los recursos entregados por la empresa significaron un cambio radical en la vida de los comuneros, tanto colectiva como individualmente, lo que ha tenido diversas consecuencias para el devenir de esta comunidad que serán revisados en este artículo. Una primera parte repasará cómo son analizados los mecanismos de resolución de conflictos ambientales en Chile, en segundo lugar, se examinará el caso de estudio, específicamente la judicialización y negociación entre la comunidad aymara de Cancosa y la empresa BHP Billiton, para finalmente revisar las consecuencias que este proceso ha tenido para la comunidad.

Esta negociación suele ser considerada como exitosa, sin embargo, este artículo presenta un análisis y evaluación de sus resultados, comprobando que no ha tenido los efectos esperados con base en las aspiraciones de desarrollo de la comunidad. La mayor parte de los comuneros habita lejos del territorio común, sin las prácticas espaciales que les permitían constituirse como comunidad aymara altoandina. Esta fragmentación ha provocado adicionalmente, la pérdida de elementos económicos, culturales y políticos, que les permitían fortalecer su identidad territorial.

La investigación utilizó análisis de contenidos de dos fuentes de información; por una parte, los documentos del expediente judicial (documentos de las demandas y sus respuestas, así como los medios de pruebas presentados por las partes), así como declaraciones públicas y otros emanados de la comunidad. Una segunda fuente de información, fueron las entrevistas realizadas a los actuales y pasados dirigentes, que lideraron tanto el proceso judicial, como el de negociación posterior. Este enfoque permitió conocer las narrativas de la negociación, pero también las percepciones y evaluaciones que surgen en la comunidad después de haber vivido esta experiencia.

\section{La negociación como una salida para los conflictos ambientales}

En momentos que iniciaba la expansión minera en Latinoamérica, la resolución de conflictos ambientales por vías alternativas crecía en distintas partes del mundo (Sabatini, 1997a; Ascelrad, 2006). Sin embargo, en Chile recién comenzaba a configurarse un marco institucional ambiental. Sólo en 1998, se promulgó la primera Ley Ambiental (Ley de Bases del Medio Ambiente $\left.\mathrm{N}^{\circ} 19.300\right)$ cuyo principal objetivo fue la certificación de las actividades económicas, más que la protección del medio ambiente. Hasta hoy y a pesar de que esta Ley ha tenido algunas modificaciones, no se ha logrado instaurar un sistema no judicial de resolución de conflictos ambientales por vías formales.

Una de las principales modificaciones que ha tenido la Ley 19.300 (2010), fue cuando se incorporaron -entre otras cosas- los tribunales ambientales. Sin embargo, estos tribunales 
que comienzan a funcionar en el año 2013, no han implicado una disminución de los conflictos ambientales, debido a que el sistema se sigue accionado con la denuncia sin incorporar mecanismos de mediación temprana (Cordero et al., 2017) pero, además no se han fortalecido la participación o los canales de información hacia las comunidades locales.

Hasta hoy, la mayor parte de estos conflictos siguen buscando solución a través de la vía judicial con o sin negociación paralela (Sabatini, 1997a; Cordero et al., 2017). Como resultado, si bien la judicialización logra disminuir considerablemente la tensión explícita, no logra la cohesión entre los actores que ocupan un territorio, por tanto, las condiciones territoriales resultantes no son las adecuadas para propiciar acciones hacia un desarrollo, tal como lo ocurrido en la comunidad aymara de Cancosa.

Especialmente desde el ámbito jurídico, se considera que las negociaciones en los conflictos ambientales, tanto por vías judiciales como extrajudiciales, deben ser incorporadas en el sistema público de gestión ambiental como un procedimiento habitual para la prevención o superación de los conflictos (Cordero et al., 2017). Más aún deben ser vistas como una oportunidad de desarrollo democrático (Sabatini y Sepúlveda, 1997). Pese a lo anterior, la negociación cuenta con muchos argumentos contrarios, como que: (i) se suele confundir los intereses o puntos de vista propios con la verdad, provocando que la negociación adopte cierta falta de objetividad (Sabatini, 1994), (ii) la diferencia de poder entre los actores que forman parte del trato es tan amplia que no es posible hablar de una verdadera negociación en estas condiciones (Crespo, 2005). Esta diferencia de poder implica que no hay reconocimiento de la legitimidad de las posiciones de los demás, como requisito fundamental para iniciar el diálogo (Sabatini, 1997b; Crespo, 2005).

El contexto en el cual se producen los conflictos ambientales y por tanto cualquier negociación para prevenirlos, aplacarlos o resolverlos, ha sido caracterizado como un escenario de enormes diferencias en cuanto al poder y la incidencia política, al nivel de conocimiento con respecto al proyecto y a sus consecuencias, así como diferencias culturales, sociales y económicas entre los intervinientes (Sabatini, 1997b; Alonso y Costa, 2002; Fuks, 2001; Acselrad, 2004).
El particular tipo de conflictos que se da producto de la resistencia local frente a los proyectos de los sectores extractivos se origina generalmente, en los temores sobre los impactos de las intervenciones en la ecología local, la economía y la cultura, a lo que se agrega la debilidad institucional y desatención del Estado, la desconfianza en el Estado como protector del ambiente así como la presunta incompatibilidad entre diversas actividades económicas (Escobar, 2006), adicionalmente cuestionamientos crecientes sobre la actuación de las empresas en los territorios y más recientemente la radicalización de posiciones anti-minería y agendas ocultas de algunos líderes y organizaciones (Bebbington, 2007) agravan la situación. Por lo tanto, estos conflictos no solo se vinculan con problemas sociales preexistentes, sino también con problemas políticos de los países en los cuales se forman, es decir, ocurrirán más conflictos en los lugares en donde el contexto político e histórico constituya una tensión en la sociedad (Leff, 1998).

Se sostiene que en todo conflicto ambiental hay negociación, porque ninguno de los actores del conflicto tiene tanto poder como para imponer su postura (Sabatini,1994 y 1997b), aun cuando ninguno de los actores cree que está negociando. Sin embargo, desde el inicio de la relación, comienzan a ocurrir procesos que obstaculizan una correcta negociación como la cooptación, o "el sutil proceso de socavar la fuerza de la parte contrincante por la vía de reducir su independencia" (Sabatini, 1994:21), el paternalismo ya sea desde el Estado o desde la empresa y la dependencia externa, mecanismos que se combinan y mezclan en la realidad.

Para que exista negociación formal debe, en primer lugar, existir una institucionalidad que asegure la rigurosidad, transparencia y justicia en el proceso, acudiendo a mecanismos creados para tales fines. Adicionalmente es necesario que estén claras las posturas de los intervinientes y tiene que haber mayor equilibrio de fuerzas entre ellos (Crespo, 2005). En países como Chile que no cuenta con estos aparatos institucionales, para que haya negociación se requiere llegar a la judicialización, la que siempre implica negociación, aunque con una salida que obliga a una resolución definitoria.

Lo que ocurre cuando las condiciones para la negociación no son las adecuadas, es lo que 
se ha denominado salidas fundamentalistas, que se dan cuando no hay equilibrio de poder y se impone el más fuerte con una visión extrema -ya sea económica o ecológica-, denominándolos conflictos de enfoque ya que escapan de la negociación técnico-científica en que se pueden resolver los conflictos de intereses. En ellos no es posible hablar de negociación (Sabatini, 1997b). Esta salida junto a la cooptación, tienen en común la desvalorización tanto, del derecho que tienen las comunidades y autoridades locales respecto de estos conflictos, como de su papel en dar una salida que garantice el desarrollo local.

Por otra parte, la judicialización que corresponde a la mayoría de los casos de conflicto en Chile puede $-\mathrm{y}$ generalmente lo hace- originar negociaciones paralelas que muchas veces interrumpen los procesos judiciales, precisamente como el caso de Cancosa. Las empresas negocian informalmente, produciendo cooptación o paternalismo, como una forma de acallar la tensión territorial y disminuir el riesgo de aparecer como perdedoras. En la práctica, el recurso judicial suele ser una vía que usan las comunidades locales para intentar equiparar fuerzas y desencadenar la negociación o entrar en mejor pie a ella. Este tipo de salida, cuando llega a término genera fuertes rupturas en el devenir territorial ya que existe un ganador y un perdedor, es decir, una postura logra imponerse sobre la otra sin que exista diálogo o acuerdo entre las partes.

Las resoluciones judiciales a pesar de lo anterior y de concentrarse excesivamente en cuestiones de forma a expensas de las de fondo, tienen la ventaja de ofrecer soluciones irreversibles y obligatorias para todos. Esta ventaja puede ser importante en situaciones altamente conflictivas o complejas, ya sea como alternativa o como complemento de la Resolución Negociada de Conflictos Ambientales (RNCA) en países donde existe formalmente.

La RNCA surgió en Estados Unidos con el nombre de Alternative Dispute Resolution (ADR) en respuesta a los movimientos de reivindicación de derechos que se desarrollaban en ese país, con gran protagonismo en la escena pública durante la década de 1960 (Nader, 1994; Siper, 1999). Luego esta estrategia deriva en la Environment Dispute Resolution (EDR), como un mecanismo diseñado especialmente para las disputas de tipo ambiental.
Las iniciativas de negociación se originan en países centrales (Estados Unidos y Canadá), que es donde mayormente han prosperado y se han institucionalizado (Sipe, 1999). De acuerdo a la investigación realizada por Acselrad (et al., 2010) las estrategias alternativas de resolución de conflictos ambientales fuera del ámbito judicial, han sido metodologías promovidas en América Latina por el Banco Mundial desde mediados de la década de los noventa, con propósitos de disminuir la creciente conflictividad ambiental que estaba produciéndose en la región a partir de la liberalización de sus economías.

Su difusión y expansión orientadas hacia la capacitación de entidades y comunidades de países periféricos, presuponiendo que la "falta de instituciones" da origen a conflictos ambientales y que "la paz y la armonía deben provenir de un proceso de despolitización de los litigios a través de tácticas de negociación directa capaces de proveer dividendos mutuos" (Ascelrad et al., 2010:29), es un enfoque que presupone un paternalismo desde los países centrales donde se origina.

Junto con revisar las normativas de la región, este autor realiza una fuerte crítica a los mecanismos de RNCA, debido a que la difusión de ellos ha ocurrido verticalmente en Latinoamérica, paralelo a la irrupción del modelo extractivo exportador (Acselrad et al., 2010). Además, se señala que la RNCA de la forma en que ocurre actualmente, despolitiza el medio ambiente (Swyngedouw, 2011), reduciendo las decisiones al ámbito científico-técnico y económico.

A pesar de aquello, solo México y Chile quedan fuera del listado de países latinoamericanos que cuentan con algún mecanismo de negociación; negociación directa, conciliación, facilitación, mediación o arbitraje (Ascelrad et al., 2010), lo que permite que exista mayor judicialización, así como mayor negociación entre las partes sin regulación ni fiscalizaciones por parte de las autoridades pertinentes. En Chile, la normativa ambiental solo exige a la empresa informar sobre la existencia de negociación "con los interesados' antes del ingreso al proceso de evaluación, como asimismo informar los planes de mitigación y compensación ambientales. Mientras que la reparación ambiental surge de procesos de fiscalización y normalmente vinculado al incumplimiento de la Resolución de Calificación 
Ambiental (RCA) que es el permiso ambiental que otorga la autoridad.

Las críticas que surgen sobre lo expuesto, se refieren a que la normativa permite que la empresa negocie con la comunidad antes de la aprobación ambiental, es decir, en esta etapa la empresa puede comprometer compensaciones como una forma de presión ante la resistencia de las comunidades locales, lo que produce cooptación. Por otra parte, y tal como menciona Crespo (2005), estas negociaciones, asumen que los actores locales se encuentran en equilibrio de fuerzas, mientras que en la mayoría de los casos los actores locales se encuentran bajo relaciones de dominación.

Adicionalmente, estos procesos irregulares no han representado algún beneficio significativo para las comunidades, ya que muchas veces la negociación de bienes, mercancías o servicios a las poblaciones locales o incluso a sus dirigentes de forma individual, hace que las operaciones mineras y sus impactos se vuelvan socialmente tolerables o incluso legítimos, lo que profundiza una situación de injusticia ambiental.

Las salidas negociadas necesitan fuertes dispositivos de regulación que aseguren justicia y transparencia en los procesos, precisan reducir la desigualdad de poder, de información, de influencia política de los negociadores, para que así los resultados de las negociaciones sean efectivos y conduzcan a procesos de desarrollo territorial.

\section{La comunidad aymara de Cancosa frente a Cerro Colorado}

La comunidad indígena aymara de Cancosa se ajusta a lo que se ha denominado comunidades ganaderas altoandinas (Vergara et al., 2014) sin embargo, a diferencia de ellas que se organizan sobre la base de la herencia patrilineal de la tierra, Cancosa tiene su origen en la migración de algunas familias desde dos comunidades de la zona de Cariquima en la década de 1940.

De acuerdo a sus propios registros, se compone de más de 80 familias, unas 350 personas, sin embargo, de acuerdo al Censo de 2002, solo 26 de ellas habitan el territorio. Aunque en la visita a terreno se constató que los habitantes permanentes no superan las 6 personas a lo que se suma unas 20 personas que visitan el lugar para cuidar su ganado y sus plantaciones de quínoa (Romero-Toledo et al., 2017). Los comuneros atribuyen este abandono a diversos factores históricos (Gundermann y Vergara, 2009), pero consideran que el impacto de la minería y el dinero recibido en la negociación constituyó el último impulso para su migración a ciudades cercanas, como Alto Hospicio, Iquique, Pica y Mamiña, donde se concentran actualmente.

...porque se está dispersando la gente de estos lugares, de otros lados, por lo mismo porque hay mineras, nuestros hijos ya viven cómodos porque vieron que hay una entrada de recursos y se fueron, porque anteriormente como no existían las mineras las gentes vivian en su pueblo, trabajando en su tierra. Pero ahora no, ya ahora las nuevas generaciones ya no quieren saber nada de acá (dirigente, hombre tercera edad, julio del 2015).

Las relaciones entre la empresa y la comunidad siempre fueron tensas, incluso desde que decidieron arrendar Lagunillas en 1991 (Mamani, 2008; Romero-Toledo et al., 2017). Sin embargo, el conflicto no se desató sino hasta el año 2002, cuando la comunidad pudo verificar que la empresa estaba consumiendo más agua de la permitida (Yañez y Molina, 2008) y como consecuencia de ello, el nivel de la laguna había bajado considerablemente. Así como algunas vertientes de agua dulce del sector y el bofedal mostraban signos de desecación.

A pesar de que ellos tenían arrendado el predio a la CMCC, mantenían en él 800 cabezas de ganado (cámelidos) lo que dejó de ser posible desde el momento en que el agua para los animales desapareció, configurando una pérdida económica $y$, en consecuencia, aumentando la amenaza sobre estas prácticas ancestrales. Por otra parte, mencionan que el daño ambiental también representa un impacto sobre los recursos paisajísticos con potencial económico relevante, puesto que en la zona ha habido una creciente demanda etnoturística, principalmente por parte de extranjeros, que ha traído importantes recursos financieros a otras comunidades indígenas de la zona.

En este sentido la comunidad ha ejecutado algunos proyectos que le permitan en el futuro transformarse en un territorio turístico. Esto ha sido impulsado especialmente por los dirigentes 
más jóvenes, puesto que ven en esta actividad la posibilidad de vínculo comunitario e incluso el eventual retorno al territorio.

El área afectada corresponde a un bofedal altoandino, un ecosistema altamente frágil, debido a las actuales variabilidades climáticas pero también por las intervenciones mineras (Romero, Méndez y Smith, 2012), las que han ejercido una enorme presión sobre los recursos hídricos de la zona altiplánica (Prieto, 2016; Salinas, 2012; Yáñez y Molina, 2008 y 2011, Romero et al., 2017). De hecho, al momento de la llegada de la compañía minería en 1985, la Dirección General de Aguas (DGA) declaró que la situación en el comportamiento de los cuerpos de agua dentro de este sector debía ser monitoreado (DGA, 1985).

Los comuneros estimaron que el daño ambiental ocasionado era tan grave que incluso podría ser considerado como un daño al patrimonio natural del Estado, tanto por la envergadura del daño, como porque el ecosistema afectado se encuentra protegido debido a sus características biológicas y culturales (Área de desarrollo indígena por Decreto Supremo del Ministerio de Planificación y Cooperación $\mathrm{N}^{\circ} 67$ de fecha 8 de marzo de 2001; Protección de bofedales altoandinos desde 1997 mediante Resolución 909 de la DGA). Por este motivo la primera acción que tomaron fue una denuncia ante el Consejo de Defensa del Estado, la que no fue acogida (Estrada, 2007). Por lo cual la comunidad vio en la resolución judicial una salida a su demanda.

Desde el año 2002 en adelante tanto el Estado, a través de los servicios de la Comisión Nacional de Medio ambiente (CONAMA) y la DGA, como la empresa, iniciaron un proceso de estudios e investigaciones para comprobar o refutar la denuncia de la comunidad. También la comunidad mandó a realizar estudios hidrogeológicos propios, que le permitieron fortalecer las pruebas de su demanda (Romero-Toledo et al., 2017).

Posteriormente, en enero de 2005, las autoridades ambientales de la Región de Tarapacá (Comisión Regional de Medio AmbienteCOREMA y DGA-Tarapacá), tras investigar el estado de situación de Pampa Lagunillas, constataron el manifiesto daño ambiental sobre casi la totalidad del bofedal, aludiendo que:

El estado de degradación del ecosistema es de tal magnitud, que estimamos que su auto-recuperación o recuperación natural ya no es posible. (Comunidad aymara de Cancosa, 2006).

Respecto a esto, la COREMA en el año 2006 estableció que las responsabilidades por este daño ambiental corresponderían a los efectos que la minera estaba causando por el uso indebido de las fuentes de agua a través de la extracción de los acuíferos que estarían mermando el equilibrio del bofedal. En el mismo año la CONAMA en la Resolución N ${ }^{\circ} 19$ estableció una multa de 1500 UTM.

Frente a ello, la CMCC inicia un Plan de Relaciones Comunitarias con las 10 comunidades indígenas más próximas al proyecto. El propósito de este plan era entregar el $1 \%$ de las utilidades para proyectos de desarrollo sustentable que presenten las comunidades. Los proyectos que se financiaron para la comunidad de Cancosa fueron un tractor y posteriormente un galpón para guardarlo (Estrella de Arica, 7 de octubre 2003).

La empresa, nunca ha reconocido que sus acciones fueron las responsables de la desecación del bofedal, en los documentos presentados en el proceso judicial hacían alusión a que la afectación del ecosistema se debía "completamente por los cambios naturales de un ecosistema que está en un lugar de fuertes fluctuaciones anuales e interanuales de las variables abióticas" (CMCC, 2005, s/p).

La comunidad consideró insuficiente la multa y las formas de reparación del bofedal desecado, es por esto que deciden judicializar el conflicto a través de dos demandas. La primera en abril de 2006, por daño ambiental con una indemnización de 40 millones de dólares la que no tuvo ninguna respuesta por parte de la empresa (Larraín y Poo, 2010), existiendo además en este período la dilatación de las posibilidades de diálogo. La segunda demanda, un año después solicitando la reparación del daño ambiental.

En marzo del año 2008, la comunidad interpone una tercera demanda. Esta solicitud sí tuvo respuesta por parte de la empresa, rechazando e invalidando cada uno de los argumentos por cuestiones administrativas como la representatividad de los dirigentes y no por las contundentes evidencias con respecto al daño ambiental ocasionado (CMCC, 2008).

Paralelamente al proceso judicial, la CMCC con la voluntad de establecer lazos con la comunidad desarrolló un plan de "ayuda mutua" en el que "apadrinó" a la comunidad a través de un aporte 
monetario de 6.000 dólares anuales, cancelados en cuatro cuotas trimestrales, que al cabo del periodo sumarán 180.000 dólares. La comunidad utiliza ese dinero para diferentes proyectos de desarrollo y actividades culturales (Mamani, 2008).

A pesar de este acuerdo entre privados que finaliza el proceso judicial, aun no existe la reparación ambiental: "hasta el día de hoy no hay recuperación como corresponde, estamos totalmente perjudicados. $\mathrm{Y}$ ahora lo que estamos pensando que va a pasar, cuando el día de mañana la minera se va a ir" (dirigente, hombre tercera edad, julio del 2015).

\section{Limitantes de la negociación informal para el desarrollo}

Este caso tiene como principal mecanismo de resolución la negociación, puesto que el conflicto desatado culmina una vez que la comunidad aymara negocia con la empresa de manera privada, terminando con ello el conflicto judicial y disminuyendo temporalmente la tensión entre los actores. El acuerdo entre las partes más que significar una alianza para el territorio se expresa como una instrumentalización entre los actores ya que no ha significado el término del conflicto ambiental.

En este caso la judicialización fue una medida de presión, pero ciertamente evidenció las limitantes que tienen tanto los procesos judiciales como las negociaciones informales en los conflictos, fundamentalmente porque en la búsqueda de una salida radical, donde prima la protección ambiental o el crecimiento económico, este último ha sido quien ha dominado en las décadas recientes. Las compensaciones económicas terminan, por tanto, justificando los daños ocasionados.

Entre las limitantes que tienen los procesos de negociación, especialmente aquellos no regulados o formalizados, se destacan la distancia entre las visiones de ambas partes con respecto, tanto a los significados que puede tener el daño ambiental, así como miradas divergentes con relación a otros intereses y valores que están en el conflicto (Sabatini, 1997b; Alonso y Costa, 2002; Acselrad, 2004)). Esto implica, que la parte con menos poder, casi siempre las comunidades locales, deben adaptarse a los lenguajes, métodos y prácticas de quienes configuran la parte dominante, casi siempre las empresas o el Estado.
Esta brecha, se hace más evidente en los casos de negociación con comunidades indígenas, situación que es reconocida por los dirigentes, quienes sostienen que la diferencia cultural está en el centro del conflicto:

Nuestros padres, nuestra comunidad no estaban preparados para una negociación de esa naturaleza, uno porque no se hablaba el mismo lenguaje, lo segundo es que las experiencias eran recién las primeras, entonces eran los primeros experimentos que surgen acá en el norte en términos de una relación con empresas y tercero es que muy vagamente veían una posibilidad de buscar ese desarrollo, tan metido en nuestras mentes ya (dirigente, hombre adulto, julio del 2015).

El proceso de aprendizaje que ha resultado del conflicto, los ha llevado a la demanda de "compromisos históricos de la compañía minera", ya que muchos de los acuerdos que la empresa mantenía con ellos eran "de palabra". Es por esto que los dirigentes han tenido que dedicar una parte importante del tiempo de la negociación en el reconocimiento de los compromisos basados en promesas realizadas por los -siempre cambiantes- representantes de la compañía durante los casi 20 años de relación. Es relevante mencionar que, la gestión jurídica implica un importante esfuerzo de organización -política y financiera- asî como de confianza entre sus participantes, por lo que hay un fuerte riesgo de generar tensiones y fragmentaciones comunitarias.

Sin duda, los procesos de negociación en conflictos ambientales, siempre serán complejos y tendrán un importante riesgo de fracaso. Su éxito dependerá de la capacidad de dar lugar al ejercicio de los derechos de los sujetos (Sabatini, 1997b). Aunque los acuerdos amplios y participativos puedan parecer más lentos y difíciles, principalmente para las empresas, sin duda aseguran la legitimidad social que permite, a largo plazo, evitar costos mayores derivados de cuestionamientos y nuevos o más profundos conflictos.

\section{La negociación como ruptura en el devenir de la comunidad}

De lo expuesto, es posible identificar algunos elementos que aparecen transversalmente en las narrativas de los comuneros y comuneras, y que dan cuenta de los efectos que ha tenido la 
negociación con la empresa minera para la permanencia y desarrollo de la comunidad aymara de Cancosa.

En primer lugar, la negociación obliga a poner en los mismos términos o "valores", elementos que pudieran tener diferentes apreciaciones para los distintos grupos de actores, es decir, la negociación obliga a medir un daño ecológico $-\mathrm{O}$ de otro ámbito- a través de un valor monetario. Incluso en casos como el analizado, donde la compensación económica ha sido significativa para el mejoramiento del nivel de vida de los habitantes, aquello no implicó la reparación del daño ambiental o el cumplimiento de los compromisos por hacerlo, sino que la compensación económica traslada el foco del problema. El peligro de esto, es que puede llegar a legitimar el daño ambiental, así como, que ciertos grupos de la sociedad validen y asuman de manera injusta las externalidades negativas del extractivismo minero.

En el caso de Cancosa el daño ambiental no ha logrado legitimarse. Para ellos el daño ambiental no solo ha significado una pérdida en términos de sus actividades económicas, sino que además implica una pérdida social, cultural e incluso religiosa.

A pesar de que el acuerdo entre la comunidad y la empresa obliga a esta última a reparar el daño ambiental ocasionado, los comuneros mencionan que esto no es posible debido a la gravedad del daño. La actual estrategia de reparación ambiental se traduce en que la empresa bombea agua desde los pozos subterráneos construidos en la misma laguna hacia su superficie permanentemente, produciendo un espejo de agua, intentando con ello recuperar la vegetación. Este ejercicio finalizará una vez que la empresa deje la faena, siendo incierto lo que ocurra con el bofedal: "cómo nos va a recuperar ese bofedal de Lagunillas como era antes, yo creo que eso es imposible" (dirigente, hombre tercera edad, julio del 2015).

Por otra parte, los comuneros que no habitan el territorio, también hacen referencia a la tensión interna que se ha manifestado por la compensación, la que ha implicado la fragmentación de la comunidad, puesto que esta -de acuerdo a su evaluación- no estaba preparada para enfrentar esa negociación, como tampoco para administrar los montos de dinero que han sido entregados por la empresa. Estos dineros se han tenido que entregar individualmente, principalmente a través de becas y otras ayudas, lo que ha generado aún más tensión al interior de la comunidad, "en este momento la comunidad se encuentra dividida, claro se encuentra dividida porque se produce la desconfianza. (...) ya no existe esa unidad que había, entonces evaluando, evaluando, ha sido negativo"(dirigente, hombre mediana edad, octubre del 2015). La fragmentación comunitaria constituye, sin duda, una dificultad para el devenir de la misma, debido a que estas tensiones se contradicen con su visión indígena de carácter colectivo.

Luego de la experiencia obtenida a partir de estos años de conflicto y negociación, los dirigentes sostienen que cada vez estaría más lejos la posibilidad de cumplir las expectativas de prosperidad deseadas y creadas a partir del acuerdo suscrito con la empresa minera. Así como, reconocen que esta fractura social ha significado un obstáculo adicional para sus trayectorias comunes que tomará tiempo recomponer, "en este momento la comunidad se encuentra dividida, la comunidad no estaba preparada para administrar ese dinero que fue entregado, hasta la fecha hay un problema de confianza" (dirigente, hombre adulto, julio dele 2015).

La contradicción se centra en que, a pesar de lo expuesto, reconocen y valoran el nivel de progreso que les ha permitido lograr la compensación económica. Pero esto ha tenido consecuencias que les han obligado a modificar su modo de vida tradicional, generando algunas tensiones entre el "ser aymara" perteneciente y habitante de una comunidad andina a transformarse en un ciudadano chileno con identidad indígena (Gunderman et al., 2014), puesto que deben ajustarse a una nueva realidad espacial producto de la migración pero además, han tenido que formarse políticamente y tener que dialogar y negociar con actores públicos y privados de alto poder político.

Estas fragmentaciones sociales, así como las visiones contradictorias sobre el territorio, se generan de manera diferenciada de acuerdo al grupo etario al que pertenecen los dirigentes. Un grupo lo constituyen los dirigentes más antiguos de la comunidad, que nacieron, estudiaron y habitaron la mayor parte de su vida en el altiplano. El segundo grupo está conformado por dirigentes jóvenes que pudieron o no haber nacido en la comunidad pero que actualmente construyen una territorialidad sin territorio, es decir, su identidad territorial se sustenta en la transmisión de valores por parte 
de sus padres y familiares, lo que los ha llevado a trabajar por desarrollar proyectos que les permitan revivir la vida indígena.

El primer grupo, los adultos, identifica la brecha que se establece entre lo que han obtenido en términos materiales y lo que ha ocurrido con la vida comunitaria, coinciden en relacionar el progreso, con el acceso a mejoras en el nivel de vida, especialmente en cuanto a la satisfacción de necesidades básicas, no obstante, sentencian que aquello no es suficiente para lograr el desarrollo sustentable o desde su perspectiva el Buen Vivir. Para ellos, su visión de desarrollo incluiría además de la satisfacción de necesidades básicas, valores comunitarios, los que mencionan como fundamentales:

Y si vemos hasta el momento tampoco Cancosa se ha desarrollado por como entiendo el desarrollo, no tiene agua potable, no tiene alcantarillado, no tiene alumbrado constante, no tiene nada, hasta el momento no tiene nada, estamos de repente en la misma situación que hace 45 años atrás (dirigente, hombre adulto, julio del 2015).

Adicionalmente consideran la cercanía con la naturaleza y el respeto a sus equilibrios, como condición fundamental para el desarrollo territorial. Es decir, las características necesarias para el futuro se asocian, contradictoriamente, a su antigua vida comunitaria, evidenciando con ello que aquella forma de vida pasada les permitía un nivel de desarrollo adecuado, incluso para sus expectativas presentes.

Esta contradicción no es tan evidente entre los dirigentes más jóvenes que no tuvieron esta experiencia de vida comunitaria, en sus visiones relevan elementos asociados al crecimiento económico de la comunidad. Este grupo, hace palpable la necesidad de conciliar lo indígena con lo occidental, a través de la educación, del diálogo, del reconocimiento y la inclusión, "eso es lo que queremos, que la gente retorne, que encuentre una forma en desarrollo económico" (dirigente, mujer joven, julio del 2015).

Finalmente, un aspecto mencionado por todos los dirigentes, es que la compensación económica recibida los distanció de otras comunidades indígenas de la zona que no han logrado beneficios económicos tan considerables, esto ha implicado que sean criticados u ofendidos públicamente.

Sostienen que la anterior forma de vida comunitaria ya no sería posible, y que están obligados a incorporar en su nueva vida valores que no corresponden a su cultura. En este sentido y más allá de las críticas, discordias y contradicciones que instaló la negociación y posterior compensación económica por parte de la empresa minera, reconocen y valoran que aquello les ha permitido acceder a ciertos espacios de la sociedad gracias a los cuales se sienten más reconocidos, es decir, no hay un "arrepentimiento" sobre la relación sostenida con la compañía minera, aunque aseguran que esto no es suficiente para lograr el ansiado desarrollo.

\section{Conclusiones}

Aún en la actualidad no existen suficientes estudios para determinar si la negociación en los conflictos ambientales, ya sea formal o informal, ha tenido los efectos esperados, así como si estos efectivamente significan mayor participación y cohesión en las comunidades locales, elementos que destacan las posturas a favor de este tipo de salidas a los conflictos ambientales.

El caso de la comunidad aymara de Cancosa que tiene como principal mecanismo de resolución la judicialización y negociación informal, muestra que aquellos procesos, por exitosos que parezcan, no significan una nueva trayectoria territorial o que el "acuerdo entre las partes", represente una alianza para el desarrollo futuro, sino que la negociación implica que esta relación se instrumentaliza, legitimando el daño ambiental y sus consecuencias y provocando, como en este caso, el abandono de los territorios.

De lo anterior es posible percibir los peligros que conlleva la judicialización y negociación en los conflictos ambientales desde la perspectiva del desarrollo, y en este caso en particular, en que este proceso provoca la pérdida de los valores asociados a la vida comunitaria, transformándose en una negociación de intereses (económicos) y no de valores.

Chile sigue siendo uno de los pocos países de América Latina que no tiene una normativa clara o una institucionalidad en relación con la mediación en conflictos ambientales y entendiendo que, efectivamente en el territorio nacional existe una 
enorme cantidad de ellos donde hay negociaciones fuera de toda normativa o resguardo, se hace necesario la regulación de estos procesos por instancias adecuadas que, o bien prohíban las negociaciones informales o la regulen en el sentido de disminuir las desigualdades entre los actores, con propósitos que se produzca una negociación justa.

Esta experiencia, muestra que es difícil hablar de éxito en la RNCA puesto que, incluso con negociaciones que implican grandes compensaciones económicas y comprometen reparación el daño producido, esto no asegura el desarrollo local. Este desarrollo dependerá de otros procesos y dispositivos económicos, pero también sociales y políticos.

\section{Agradecimientos}

Esta investigación fue posible gracias al apoyo del Centro de Estudios Interculturales e IndígenasCIIR (CONICYT/FONDAP/15110006).

\section{Referencias citadas}

Acosta, A.

2010 "Maldiciones que amenazan la democracia". Nueva Sociedad, No 229, pp. 42-61. Recuperado de http:// biblioteca.hegoa.ehu.es/downloads/18882/\%2Fsystem $\% 2$ Fpdf $\% 2$ F $2842 \% 2$ FMaldiciones_que_amenazan la_democracia.pdf

Acosta, A.

2012 Extractivismo y neoextractivismo: Dos caras de la misma maldición. En Grupo permanente de trabajo sobre alternativas al desarrollo, Más allá del desarrollo, Fundación Rosa Luxemburgo. Quito: Abya Yala. pp. 83118. Recuperado de http://polodemocratico.co/pdf/ Alberto\%20Acosta.pdf

Alonso, A . y Costa, V.

2002 "Por uma Sociologia dos conflitos ambientais no Brasil". En. Alimonda, H. (comp.) Ecología política. Naturaleza, sociedad y utopía. Buenos Aires: CLACSO. Acselrad, H. (Org.)

2004 Conflitos ambientais no Brasil. Rio de Janeiro: Relume-Dumará: Fundação Heinrich Boll.

Acselrad, H.; Das Neves, G. y Edwin Muñoz, E.

2010 "Inserción económica internacional y 'resolución negociada' de conflictos ambientales en América Latina”. Eure, Vol. 36 (107), pp. 27-47. Recuperado de https://scielo.conicyt.cl/scielo. php?script=sci_arttext\&pid=S0250-71612010000100002

Bebbington, A.

2007 "Una ecología política de la minería y la transformación territorial”. En Bebbington, A. (ed.) Minería, movimientos sociales y respuestas campesinas. Una ecología política de transformaciones territoriales. Lima: IEP-CEPES. pp. 23-46. Recuperado de http://biblio.flacsoandes.edu.ec/catalog/resGet.php?resId=21087

Compañía Minera Cerro Colorado

3 mayo 2005 Contesta demanda. Tercer juzgado de letras, Sección civil, Iquique.

Compañía Minera Cerro Colorado

26 mayo 2008 Contesta demanda. Tercer juzgado de letras, Sección civil, Iquique.

Comunidad indígena Aymara de Cancosa

25 de abril de 2006 Demanda indemnización perjuicios por daño ambiental. Tercer juzgado de letras, Sección civil, Iquique.
Cordero, L., Durán, V., Palacios, C., Rabi, V., Sanhueza, A. y Urquiza, A.

2017 Derribando mitos: propuestas para mejorar el acceso a la justicia ambiental en Chile. Informe de Políticas publicas $\mathrm{N}^{\circ} 13$. Espacio Público. Chile.

Crespo, C.

2005 "La negociación como dispositivo para reducir relaciones de dominación: aspectos conceptuales y metodológicos". En: Correa, D y Rodríguez I. (comp.) Encrucijadas ambientales en América Latina (pp. 237-256). San José de Costa Rica: Programa C y C-Universidad para la paz.

Dirección General de Aguas-DGA

7 marzo $2005 \mathrm{~N}^{\circ} 1985$ Oficio Ordinario $\mathrm{N}^{\circ} 113$.

Escobar, A.

2006 "Difference and conflict in the struggle over natural resourses: a political ecology framework". Development. Vol. 49 (3), pp. 6-13. Recuperado de https://link.springer. com/article/10.1057/palgrave.development.1100267

Estrada, D.

2007 BHP Billiton destruye bofedal en comunidad aymara de Cancosa, Aymaras versus minera transnacional. IPS. Recuperado de http://www.olca.cl/oca/chile/region01/ mineras011.htm

Estrella de Arica

7 de octubre de 2003 Minera Financiara proyectos Consultado el 25 septiembre 2015. Recuperado de: http://www.estrellaarica.cl/site/edic/20031007012517/ pags/20031007055444.html

Fuks, M.

2001 Conflitos ambientais no Rio de Janeiro: ação e debate nas arenas públicas. Rio de Janeiro: Editora da UFRJ.

Gudynas, E.

2009 "Diez tesis urgentes sobre el nuevo extractivismo. Contextos y demandas bajo el progresismo sudamericano actual". En: Extractivismo, política y sociedad. Quito: CAAP-CLAES. (pp. 187-225) Recuperado de http://www.gudynas.com/publicaciones/ GudynasNuevoExtractivismo10Tesis09x2.pdf

Gudynas, E.

2010 "Si eres tan progresista ¿Por qué destruyes la naturaleza?. Neoextractivismo, izquierda y alternativas". 
Ecuador Debate. No 79 , pp. 61-82. Recuperado de http:// hdl.handle.net/10469/3531

Gundermann, H. y J. Vergara

2009 "Comunidad, Organización y Complejidad Social Andinas en el Norte de Chile". Estudios Atacameños. $\mathrm{N}^{\circ}$ 38, pp. 107-126. Recuperado de http://dx.doi. org/10.4067/S0718-10432009000200008

Larrain, S. y Poo, P. (eds.)

2010 Conflictos por el Agua en Chile, Entre los Derechos Humanos y las Reglas del Mercado. Chile: Ediciones Chile Sustentable.

Leff, E.

1998 Saber Ambiental: sustentabilidad, racionalidad, complejidad, poder. México: Siglo XXI.

Mamani, A.

2008 "Desecamiento laguna sector lagunilla en el territorio ancestral de la comunidad de Cancosa". En Bello, A. y Alwyn, J. (comp.) Globalización derechos humanos y pueblos indígenas (pp. 392-397). Temuco: Observatorio de derechos de los pueblos indígenas .

Nader, L.

1994 Harmonía Coerciva - a economía política dos modelos jurídicos. Revista Brasileira de Ciências Sociais. $\mathrm{N}^{\circ}$ 26. São Paulo: ANPOCS.

Prieto, $\mathrm{M}$.

2016 "Transando el agua, produciendo territorios e identidades indígenas: el modelo de aguas chileno y los atacameños de Calama". Revista de Estudios Sociales. $\mathrm{N}^{\circ} 55$, p. 88-103.

Romero, H.; Méndez, M. \& Smith, P.

2012 "Mining Development and Environmental Injustice in the Atacama Desert of Northern Chile". Environmental Justice. Vol. 5(2), pp. 70-76.

Romero Toledo, H.; Videla, A. y Gutiérrez, F.

2017 Estudios atacameños. $\mathrm{N}^{\circ}$ 55, pp. 231-250. Recuperado de https://scielo.conicyt.cl/pdf/eatacam/n55/ aop1917.pdf

Sabatini, A.

1994 Espiral histórica de conflictos ambientales: Caso de Chile. Ambiente y Desarrollo-Diciembre, pp. 15-22.
Recuperado de http://cipmachile.com/web/200.75.6.169/ RAD/1994/4_Sabatini.pdf

Sabatini A.

1997a "Chile: conflictos ambientales locales y profundización democrática". Ecología política $\mathrm{N}^{\circ} 13$, pp. 51-69.

Sabatini A

1997b "Conflictos ambientales y desarrollo sustentable de las regiones urbanas". EURE, Vol. XXII (68), pp. 77-91.

Sabatini F. y Sepúlveda, C.

1997 Conflictos ambientales entre la globalización y la sociedad civil. Santiago de Chile: Cipma

Salinas, J.

2012 "La comunidad aymara de Cancosa y los acuerdos con la Compañía Minera Cerro Colorado". En: Fernández, M. y Salinas, J. (compiladores). Defensa de los Derechos Territoriales en Latinoamérica. Santiago de Chile: RIL Editores, p. 211-248.

Sipe, N.

1999 "Environmental mediation in Australia: comparisons and contrasts with the US", ADR Bulletin. Vol. 2: $\mathrm{N}^{\circ} 4$, Article 2.

Svampa, M.

2013 "Consenso de los Commodities y lenguajes de valoración en América Latina". Revista Nueva Sociedad $\mathrm{N}^{\circ}$ 244, pp. 30-46. Recuperado de: http://nuso.org/media/ articles/downloads/3926_1.pdf

Swyngedouw, E.

2011 "La naturaleza no existe". Urban. N N 01, pp. 41-66. Recuperado de https://dialnet.unirioja.es/descarga/articulo/3762434.pdf.

Vergara, J.; Gundermann, H. y Foerster, R.

2014 Estado, Conflicto étnico y cultura. Estudios sobre pueblos indígenas de Chile. Santiago de Chile: Ocho libros.

Yáñez, N. y Molina, R.

2008 La gran minería y los derechos indígenas en el norte de Chile. Chile: LOM Ediciones.

Yáñez, N. y Molina, R.

2011 Las aguas indígenas en Chile. Santiago de Chile: LOM Ediciones. 